\title{
BMP2-loaded hollow hydroxyapatite microspheres exhibit enhanced osteoinduction and osteogenicity in large bone defects
}

This article was published in the following Dove Press journal:

International Journal of Nanomedicine

12 January 2015

Number of times this article has been viewed

\section{Long Xiong' \\ Jianhua Zeng' \\ Aihua Yao ${ }^{2}$ \\ Qiquan $\mathrm{Tu}^{3}$ \\ Jingtang $\mathrm{Li}^{\prime}$ \\ Liang Yan ${ }^{4}$ \\ Zhiming Tang'}

'Department of Osteology, People's Hospital of Jiangxi Province,

Nanchang, Jiangxi, People's Republic of China; ${ }^{2}$ School of Materials Science and Engineering, Tongji University, Shanghai, People's Republic of China; ${ }^{3}$ Department of Osteology, People's Hospital of Jiujiang County, Jiujiang, Jiangxi, People's Republic of China; ${ }^{4}$ Department of Osteology, The Third Hospital of Nanchang City, Nanchang, Jiangxi, People's Republic of China
Correspondence: Long Xiong

Department of Osteology, People's

Hospital of Jiangxi Province, I52 Ai

Guo Road, Nanchang, Jiangxi 330006,

People's Republic of China

Tel +86 79I 86896216

Fax $+8679 \mid 86895863$

Email ncxionglong2@।26.com
Abstract: The regeneration of large bone defects is an osteoinductive, osteoconductive, and osteogenic process that often requires a bone graft for support. Limitations associated with naturally autogenic or allogenic bone grafts have demonstrated the need for synthetic substitutes. The present study investigates the feasibility of using novel hollow hydroxyapatite microspheres as an osteoconductive matrix and a carrier for controlled local delivery of bone morphogenetic protein 2 (BMP2), a potent osteogenic inducer of bone regeneration. Hollow hydroxyapatite microspheres $(100 \pm 25 \mu \mathrm{m})$ with a core $(60 \pm 18 \mu \mathrm{m})$ and a mesoporous shell $\left(180 \pm 42 \mathrm{~m}^{2} / \mathrm{g}\right.$ surface area) were prepared by a glass conversion technique and loaded with recombinant human BMP2 $(1 \mu \mathrm{g} / \mathrm{mg})$. There was a gentle burst release of BMP2 from microspheres into the surrounding phosphate-buffered saline in vitro within the initial 48 hours, and continued at a low rate for over 40 days. In comparison with hollow hydroxyapatite microspheres without BMP2 or soluble BMP2 without a carrier, BMP2-loaded hollow hydroxyapatite microspheres had a significantly enhanced capacity to reconstitute radial bone defects in rabbit, as shown by increased serum alkaline phosphatase; quick and complete new bone formation within 12 weeks; and great biomechanical flexural strength. These results indicate that BMP2-loaded hollow hydroxyapatite microspheres could be a potential new option for bone graft substitutes in bone regeneration.

Keyword: bone graft, bone regeneration, synthetic bone substitutes

\section{Introduction}

Large bone defects resulting from trauma, malignancy, or congenital disease are hardly regenerable without a surgical repair. ${ }^{1}$ Though autogenic and allogenic bone grafts are two conventional treatments with success in many instances, these procedures also present common problems such as donor-site morbidity, disease transmission, adverse host immune rejection, and limited supply of donor tissue. ${ }^{2-6}$ Synthetic bone graft substitutes eliminate these problems and have shown promise to eventually substitute for conventional natural grafts. ${ }^{7-8}$ However, most synthetic bone grafts have a limited capacity to reconstitute bone in large defects because they either lack natural bone growth factors, such as bone morphogenetic proteins (BMPs), platelet-derived growth factor, transformation growth factors, etc, to support osteoinductivity and osteogenicity, or fail to provide a controlled release of these factors for successful bone regeneration. ${ }^{4}$

BMPs are potent osteoinductive factors that have been evaluated extensively for both preclinical and clinical use..$^{9-11}$ They can regulate the function and differentiation of cells involved in bone formation and healing. ${ }^{12-14}$ Recombinant human BMP2 (rhBMP2) has received three US Food and Drug Administration approvals, and is 
widely used on- and off-label in the treatment of a variety of bone-related conditions. ${ }^{15}$ However, direct injection of soluble BMPs into an affected site is not effective for bone regeneration due to rapid diffusion. Hence, sustained delivery is often provided through a variety of organic or inorganic materials. Among them, hydroxyapatite (HA) has shown several striking advantages over other carriers for BMP2 delivery to regenerate large bone defects. ${ }^{10,16-19} \mathrm{HA}$ is a bioactive ceramic with chemical composition similar to the mineral component of bone, which accounts for its excellent biocompatibility and osteoconductivity. ${ }^{20-22}$ HA has been used in bone repair for bone augmentation, coating implants, and as bone filler. ${ }^{23}$ Most delivery systems are typically fabricated with porous particles, granules, or scaffolds in which the bioactive protein is either adsorbed or affixed to the surfaces of the porous material, or encapsulated within the pores. ${ }^{24-26} \mathrm{~A}$ disadvantage of these systems is the rapid release rate of bioactive proteins due to a limited surface area to entrap enough proteins. This, of course, would significantly impact the osteoinductive ability of BMPs.

The hollow HA microsphere technology was recently developed to meet the need of controlled release and prolonged delivery of bioactive proteins or drugs into target sites. ${ }^{16,27}$ In comparison to other systems, hollow HA microspheres have a hollow core and a shell wall with numerous mesopores that provide a large surface area for loading proteins and prolonging their release by desorption and migration through the mesopores. ${ }^{16}$ In the current study, we prepared BMP2-loaded hollow HA microspheres, and evaluated their therapeutic activities as synthetic bone graft substitutes in a rabbit radial bone defect model.

\section{Materials and methods Preparation and characterization of hollow HA microspheres}

The preparation of hollow HA microspheres was a two-step process as described previously. ${ }^{28}$

\section{Production of glass microspheres}

The borate glass, with a composition (wt\%) of $10 \mathrm{Li}_{2} \mathrm{O}$, $10 \mathrm{CaO}$, and $80 \mathrm{~B}_{2} \mathrm{O}_{3}$, was prepared by melting a mixture of Reagent grade $\mathrm{CaCO}_{3}, \mathrm{Li}_{2} \mathrm{CO}_{3}$, and $\mathrm{H}_{3} \mathrm{BO}_{3}$ in a Pt crucible in air for 10 minutes at $1,100^{\circ} \mathrm{C}$ and quenching between two steel plates. Particles with a size range of 106-125 $\mu \mathrm{m}$ were obtained by crushing the glass and sieving through 120 and 140 mesh sieves. These glass particles were subsequently shaped to microspheres through a flame spray process at $800^{\circ} \mathrm{C}$, as described elsewhere. ${ }^{29}$

\section{Conversion of glass microspheres}

Hollow HA microspheres were prepared by reacting these glass microspheres for 2 days in $0.02 \mathrm{M} \mathrm{K}_{2} \mathrm{HPO}_{4}$ solution $(\mathrm{pH}=9.0)$ at $37^{\circ} \mathrm{C}$. The converted microspheres were washed with deionized water, dried at $60^{\circ} \mathrm{C}$ for 24 hours, and sintered at $600^{\circ} \mathrm{C}$ for 2 hours.

Hollow HA microspheres were characterized using methods described in a previous study. ${ }^{28}$ In brief, the microstructure of both the external surface and cross-section of the microspheres was examined, and the external and internal diameters of multiple spheres were measured using scanning electron microscopy (S-2360; Hitachi Ltd., Tokyo, Japan). The rupture strength of individual HA microsphere was measured in a nano-mechanical testing system (Agilent Technologies, Santa Clara, CA, USA) using the procedure previously described.$^{30}$ The phase composition of microspheres was analyzed using X-ray diffraction (XRD) (D/ max 2550; Rigaku International Corp., Woodlands, TX, USA), and the functional groups of microspheres was characterized by Fourier transform infrared (FTIR) spectroscopy (Nicolet 560; Nicolet Instrument Corporation, Madison, WI, USA). The surface area and pore size distribution of microspheres were measured using nitrogen adsorption and calculated using Brunauer-Emmett-Teller and BarrettJoiner-Halenda methods, respectively. ${ }^{31-32}$

\section{Loading the hollow HA microspheres with rhBMP2}

According to our preliminary results, hollow HA microspheres have a maximal loading capacity of $39.4 \mathrm{mg} / \mathrm{g}$ for rhBMP2. The hollow HA microspheres were loaded with rhBMP2 (Bioss Biotech Co Ltd, Beijing, People's Republic of China) as described previously. ${ }^{33}$ In brief, $100 \mathrm{mg}$ of hollow HA microspheres were placed in a $15-\mathrm{mL}$ centrifuge tube, and $500 \mu \mathrm{L}$ of rhBMP2 solution $(200 \mu \mathrm{g} / \mathrm{mL}$, $\mathrm{pH}=3.0$ ) was pipetted into the microspheres. A small vacuum $(<0.085 \mathrm{MPa})$ was applied to the system to dispel the air in the hollow HA microspheres with the rhBMP2 solution. After 10 minutes, the BMP2-loaded microspheres were washed with phosphate-buffered saline (PBS) and dried overnight in a refrigerator at $4^{\circ} \mathrm{C}$. The loading process was completed under the hood to keep sterile.

\section{Measurement of BMP2 release in vitro}

To measure the release of BMP2 from microspheres, $100 \mathrm{mg}$ of BMP2-loaded HA microspheres was added to $10 \mathrm{~mL}$ of PBS $(\mathrm{pH}=7.04)$, and incubated with constant shaking (135 rpm) at $37^{\circ} \mathrm{C}$. Fourteen equal releases were run simultaneously 
and each covered three time points (the last one covered two time points). At 2, 4, 6, and 24 hours, and at each additional 24-hour interval until 960 hours, $4 \mathrm{~mL}$ of supernatant sample was removed for testing, and replaced with equal volume of PBS. The protein concentration of each collected sample was measured by high-performance liquid chromatography with known amounts of BMP2 as control. The accumulated BMP2 release at each time point was calculated as the sum of the remaining amount plus removed amounts.

\section{Ethics statement}

All animal studies were approved by the Nanchang University's Institutional Animal Care and Use Committee (IACUC) and were in accordance with the Guidelines for Care and Use of Experimental Animals.

\section{Animal models}

All animals were provided by the Medical School of Nanchang University, People's Republic of China. Fortyeight New Zealand White male rabbits, all 24 weeks old with a weight range of $3.0-3.5 \mathrm{~kg}$, were divided into three groups (A, B, and C) of 16 each. Group A received administration of BMP2-loaded hollow HA microspheres, group B received hollow HA microspheres without $\mathrm{BMP} 2$, and group $\mathrm{C}$ received direct injection of soluble BMP2 into the manipulated bone defect site. Animals in each group were further subdivided into four subgroups of four rabbits each, and then studied at 4 weeks, 8 weeks, 12 weeks, and 16 weeks, respectively. The level of serum alkaline phosphatase (ALP) of each animal was measured before the surgical procedure.

\section{Surgery}

All animals were anesthetized intramuscularly with 3\% pentobarbital sodium $(3 \mathrm{mg} / \mathrm{kg})$. The left radius of each animal in all groups was prepared for surgery. A 3-4 cm longitudinal skin incision was made, and the space between extensor and flexor muscle groups was dissected to expose the radial bone. A $12 \mathrm{~mm}$ length of segmental bone defect was created in the middle of the radius shaft using a delicate orthopedic saw. The defect site was irrigated with physiological saline before treatment. In groups $\mathrm{A}$ and $\mathrm{B}$, the bone defect was packed with BMP2-loaded hollow HA microspheres and hollow HA microspheres without BMP2, respectively. In group $\mathrm{C}$, the defect was left empty, but injected with equal amount of soluble rhBMP2 $(500 \mu \mathrm{g} / \mathrm{mL} \times 0.2 \mathrm{~mL})$. The incision was closed with stitches and covered with a bandage. Following surgery, the animals were administered penicillin (200 KU/kg, intramuscular injection) for 3 days, and moni- tored daily for regular day-to-day activity, food intake, and clinical signs of infection.

\section{Serum ALP test, Lane-Sandhu X-ray scoring, and 3-D image restructuring}

At weeks 4, 8, 12, and 16 post-operation, four animals in each group were randomly selected and evaluated for serum ALP level, Lane-Sandhu X-ray scoring, and 3-D image reconstruction of the radius. In brief, blood samples were collected from the marginal artery of the external ear of the rabbit. The whole blood was allowed to clot at room temperature for about 20 minutes, and the clot was removed by centrifuging at $1,500 \times g$ for 10 minutes in a refrigerated centrifuge. The serum ALP activity was measured using an automated chemistry analyzer (AU-5400; Olympus Corporation, Tokyo, Japan). ${ }^{34}$ Radiographs of bone defects were obtained to assess bone healing and new bone formation following instructions with triple blinding according to the Lane-Sandhu X-ray scores. ${ }^{35}$ Bone scanning was performed with GE Healthcare micro-CT (GE Healthcare, Milwaukee, WI, USA) and 3-D images were reconstructed using the Microview 2.2 software (GE Healthcare) to evaluate the repair progress. ${ }^{36}$

\section{Histological evaluation}

The histopathological evaluation was carried out immediately after biomechanical testing in the injured area of each animal. Sagittal sections containing the defect were cut with a slow-speed saw. Each slice was then fixed in 10\% neutral buffered formalin. The specimens were decalcified in $15 \%$ buffered formic acid solution and embedded in paraffin using standard histological techniques. Two 5- $\mu \mathrm{m}$ sections were cut from the center of each specimen, stained with hematoxylin and eosin, and examined under a light microscope (BX60; Olympus Corporation) fitted with a digital camera (DP71; Olympus Corporation). The new and original bone were identified by the presence of woven and lamellar bone at the edge of the defect, respectively. In each group, four animals per time point were evaluated for percent new bone formation and representative images were captured.

\section{Radionuclide bone imaging}

As described previously, ${ }^{37}$ animals at 4, 8, 12, and 16 weeks post-surgery were given an intravenous injection of 18.5 MBq/kg bolus 99mTc-methylene diphosphonate (99mTc-MDP) through the ear vein following anesthesia. Five images at a speed of 5 images/minute were collected as blood pool phase, and the middle image was selected for comparison. Four hours later, images at a speed of one image per 5 minutes were collected as whole-body static images, 
ie, the static phase. Pegasys Software Package was used to identify regions of interest (ROI) $(0.5 \times 0.5 \mathrm{~cm})$ at the intact side as well as the affected side. The average counts from ROI from both sides were recorded and the intake ratio was compared amongst different groups.

\section{Biomechanical test}

In order to evaluate the mechanical stability of the regenerated bones, specimens from groups A and B at the time points of 4 , 8,12 , and 16 weeks were subjected to a three-point bending test by using a mechanical testing facility (Model HY-0230, Shanghai Heng Yi Precision Instrument, Shanghai, People's Republic of China) at ambient temperature and humidity. ${ }^{36}$ In brief, the specimens were positioned on two supports spaced $8 \mathrm{~mm}$ apart, and the bending load was applied at the midpoint of the specimen at a constant displacement rate of $5 \mathrm{~mm} / \mathrm{min}$ to break (Figure 8A). The data generated in the measurement were automatically recorded.

\section{Statistical analysis}

All quantitative data were analyzed with SPSS17.0 (SPSS Inc., Chicago, IL, USA). Statistical comparisons were carried out using Student's $t$-test analysis. Statistical significance was attained with greater than $95 \%$ confidence level $(P<0.05)$.

\section{Results}

\section{Characteristics of hollow HA microspheres}

The scanning electron microscopy images in Figure 1A and B show the surface and cross-section of prepared hollow HA microspheres, respectively. They were generally uniform with an external diameter $100 \pm 25 \mu \mathrm{m}$, a hollow core of internal diameter $60 \pm 18 \mu \mathrm{m}$, and a mesoporous shell wall. The surface of the microspheres was coarse and highly porous with a pore size of $11.5 \pm 2 \mathrm{~nm}$, and the area measured by the Brunauer-Emmett-Teller method was $180 \pm 42 \mathrm{~m}^{2} / \mathrm{g}$. The rupture strength of the prepared HA microspheres was

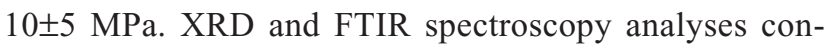
firmed that the hollow microspheres had a structure and composition corresponding to a standard HA-type (JCPDS 72-1243) material as reported in our previous study. ${ }^{28} \mathrm{On}$ the other hand, the XRD patterns showed broader and less-intense peaks than the standard HA, suggesting that the as-prepared HA was composed of nanometer-sized crystals, poorly crystallized crystals, or a combination of both. The FTIR spectra indicated that the conversion product was a carbonate substituted HA, similar to that found in living bone. ${ }^{28}$

\section{BMP2 release profile in vitro}

The amount of BMP2 released at selected time points from HA microspheres into the surrounding PBS is shown in Figure 2. BMP2 was released at a relatively high rate within the initial 48 hours with a cumulative release percentage of $31.8 \%$. The speed at which BMP2 was released slowed considerably from day 3 to a rate of about $3 \%$ per day, and after 12 days it further slowed to a nearly constant rate of about $1.2 \%$ per day until day 26 . The total release period lasted over 40 days with a final cumulative release percentage of $86 \%$.
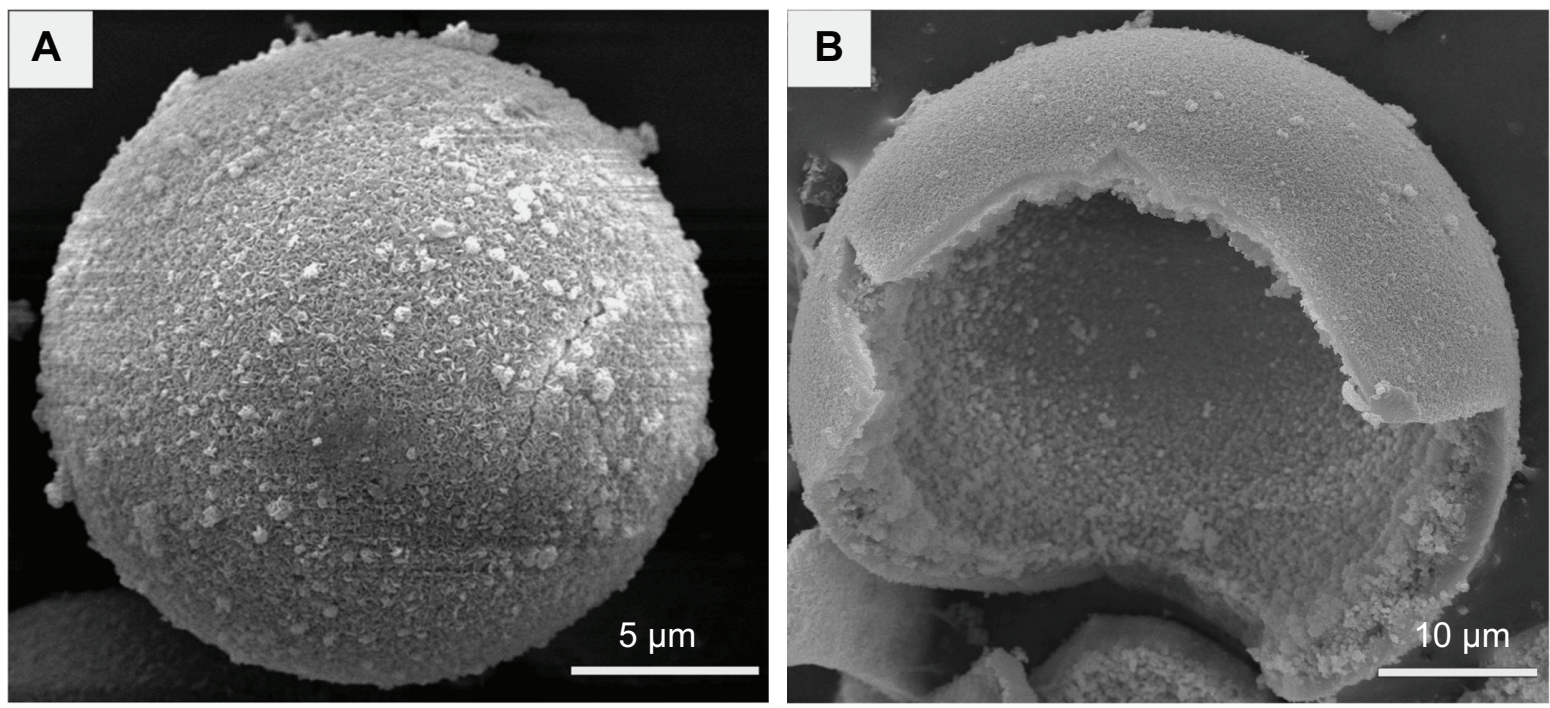

Figure I Scanning electron microscopy images of hollow hydroxyapatite microspheres.

Notes: (A) External surface under low magnification. (B) Fractured section under high magnification. 


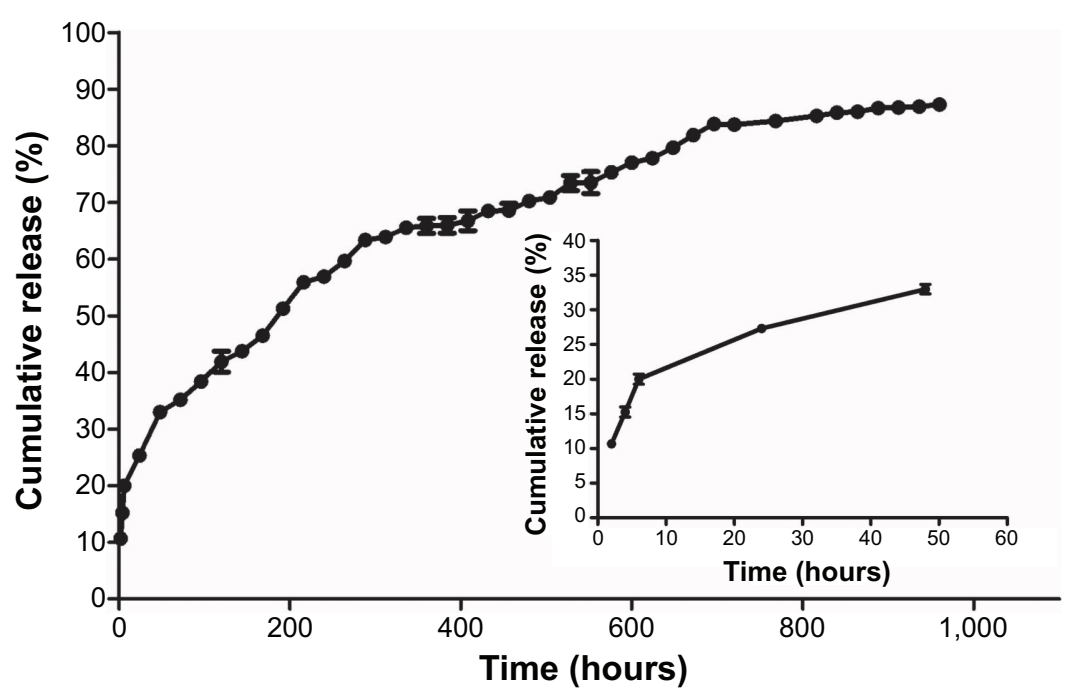

Figure 2 Cumulative release of recombinant human bone morphogenetic protein 2 (rhBMP2) from hollow hydroxyapatite microspheres into phosphate-buffered saline. Note: The insert graph shows an initial burst release within 48 hours.

\section{Therapeutic activity in vivo}

\section{Serum ALP}

Since serum ALP is an important indicator of bone regeneration, we first tracked its variation in the time course of pre- and post-operation within each group. As shown in Figure 3, the serum ALP activity in all three groups increased and reached the highest level at 8 weeks post-surgery, but group A showed a significantly higher ALP level than groups $\mathrm{B}$ and $\mathrm{C}$ at all time points post-operation, and group $\mathrm{B}$ was comparatively higher than group $\mathrm{C}$ at 4,8 , and 16 weeks $(P<0.05)$.

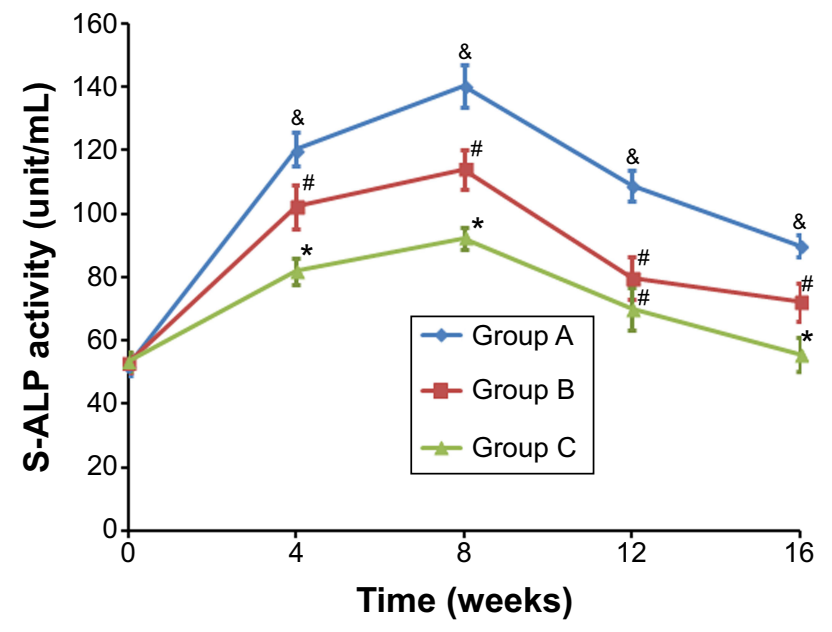

Figure 3 Serum alkaline phosphatase level.

Notes: Group A: BMP2-loaded hollow HA microspheres; Group B: hollow HA microspheres without BMP2; Group C: soluble BMP2 without a carrier. Different symbols $\left({ }^{\&}\right.$,, , and $\left.{ }^{*}\right)$ represent different serum alkaline phosphatase activities at each time point $(P<0.05)$. $N=4 /$ group/time point.

Abbreviations: HA, hydroxyapatite; BMP2, bone morphogenetic protein 2; S-ALP, serum alkaline phosphatase.

\section{Bone regeneration and quantification}

$\mathrm{X}$-ray radiography in Figure 4 shows new bone formation in each of the three groups. Bone callus was observed in groups A and B at 4 weeks, but was barely seen in group C. At 8 weeks, there was no apparent change in group C. However, HA from implants were highly degraded in group A and partially in group $\mathrm{B}$, and callus was found to bridge the distal ends of the defects in groups A and B. At 12 weeks, HA almost disappeared in group A and was substantially degraded in group B. Medullary cavities between the two ends of the fractured region were mostly connected in group A, but were not yet connected in group B. At 16 weeks, group $A$ achieved complete healing with extensive bone formation and medullary cavity recanalization; group B showed incomplete bone repair with the defect filled with callus, and medullary cavities only partially connected. Group $\mathrm{C}$ did not achieve a complete heal, with unrepaired sections remaining where non-union of bone existed.

Quantitative assessment of X-ray radiographs was performed using Lane-Sandhu radiographic score standards with results shown in Table 1. At all examined time points $(4,8,12$, and 16 weeks), the scores in groups A and B were higher than those of group C. At 4, 12, and 16 weeks, the scores in group A were higher than those of group B $(P<0.05)$. These scores reflect different levels of bone repair in three groups $(\mathrm{A}>\mathrm{B}>\mathrm{C})$.

The 3-D restructured imaging was conducted at 4 and 16 weeks to investigate the in vivo osteoinductivity of hollow HA microspheres loaded with rhBMP2 (Figure 5). In comparison to group B, group $\mathrm{A}$ had a quick bone repair rate 

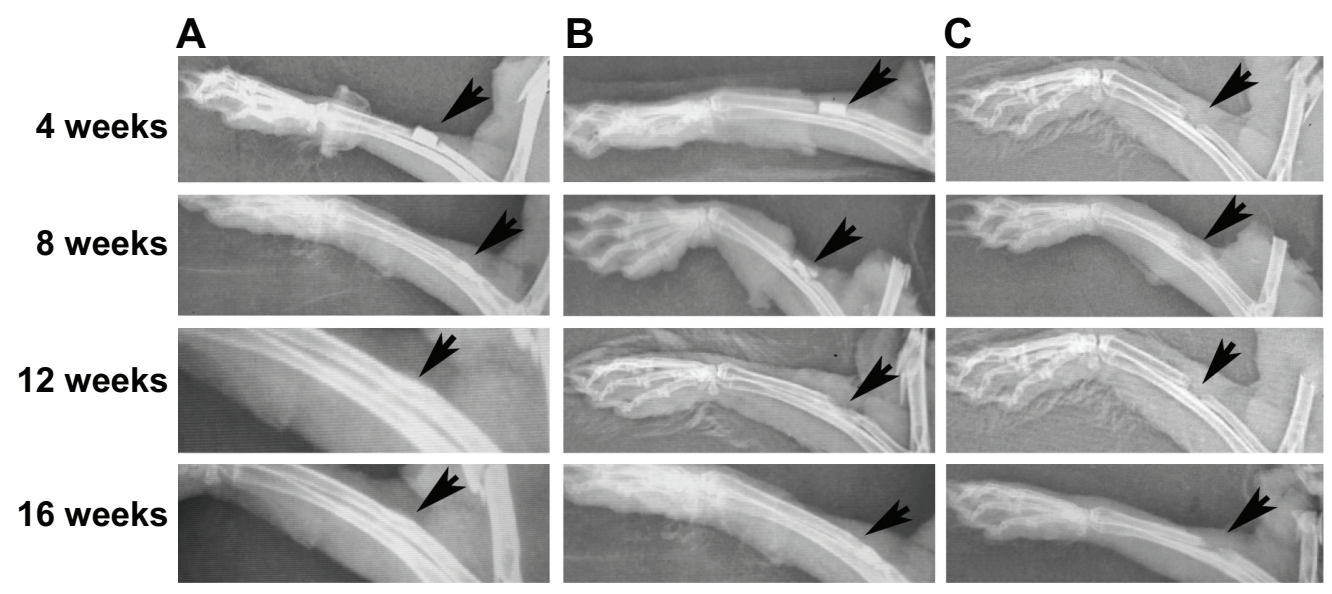

Figure 4 X-ray images of segmental radius at 4, 8, 12, and 16 weeks with different implants.

Notes: (A) BMP2-loaded hollow HA microspheres; (B) hollow HA microspheres without BMP2; (C) soluble BMP2 without a carrier. Arrows: defective and repairing sites. Abbreviations: HA, hydroxyapatite; BMP2, bone morphogenetic protein 2.

with obvious callus that bridged the HA material and defect end as early as 4 weeks. Group $\mathrm{C}$ had the least bone formation and remained non-united until 16 weeks.

\section{Histology}

Photomicrographs of hematoxylin and eosin stained sections crossing the affected bone in the three representative groups are presented in Figure 6. In group A, both graft material and newly regenerated bones were identified at 4 weeks. By week 8, implanted materials were considerably degraded; however, new bone formation was significant. At 12 weeks, new lamellar bones were developed with osteons embedded in the bone matrix, and obvious vessels in the central canals of the Haversian system. At 16 weeks, bone defects were completely recovered. Group B showed small but detectable amounts of new bone formation at 4 weeks, with HA materials partially degraded. However, evidence of increased new bone formation was present at 8 weeks. New vessels and abundant osteogenicity were visible at 12 weeks, and defect recovery mostly completed with new lamellar bones was present at 16 weeks. In comparison to groups $\mathrm{A}$ and $\mathrm{B}$, group $\mathrm{C}$ without HA implanted showed only inflammatory cells at the defective sites at 4 weeks, followed by many new fibrous tissues produced during the

Table I Lane-Sandhu radiographical bone formation score (mean \pm standard deviation)

\begin{tabular}{lllll}
\hline Group & $\mathbf{4}$ weeks & $\mathbf{8}$ weeks & I 2 weeks & I6 weeks \\
\hline A & $4.00 \pm\left. 0.966\right|^{\mathrm{a}, \mathrm{b}}$ & $6.25 \pm 1.1382^{\mathrm{a}, \mathrm{b}}$ & $9.88 \pm 1.1230^{\mathrm{a}, \mathrm{b}}$ & $11.75 \pm 0.500^{\mathrm{a}, \mathrm{b}}$ \\
$\mathrm{B}$ & $2.94 \pm 0.7719^{\mathrm{a}}$ & $5.17 \pm 1.0300^{\mathrm{a}}$ & $8.63 \pm 0.9160^{\mathrm{a}}$ & $10.00 \pm 0.8165^{\mathrm{a}}$ \\
C & $0.94 \pm 0.7719$ & $2.50 \pm 0.5222$ & $3.00 \pm 0.7559$ & $3.50 \pm 0.5774$ \\
\hline
\end{tabular}

Notes: ${ }^{\mathrm{a}} \mathrm{A}$ or $\mathrm{B}$ versus $\mathrm{C}, \mathrm{P}<0.05$; ${ }^{\mathrm{b}} \mathrm{A}$ versus $\mathrm{B}, \mathrm{P}<0.05$; $\mathrm{n}=4$ /group/time point. later weeks. No mature new bone was found, and defect recovery failed at 16 weeks. The percent of new bone formation in the defects of the three groups is shown in Table 2. In each group, the average percentage of new bone formation increased from 4 weeks to 16 weeks, but was significantly higher in the defects implanted with BMP2-loaded HA (group A) than in those without BMP2 (group B) or HA (group $\mathrm{C}$ ).
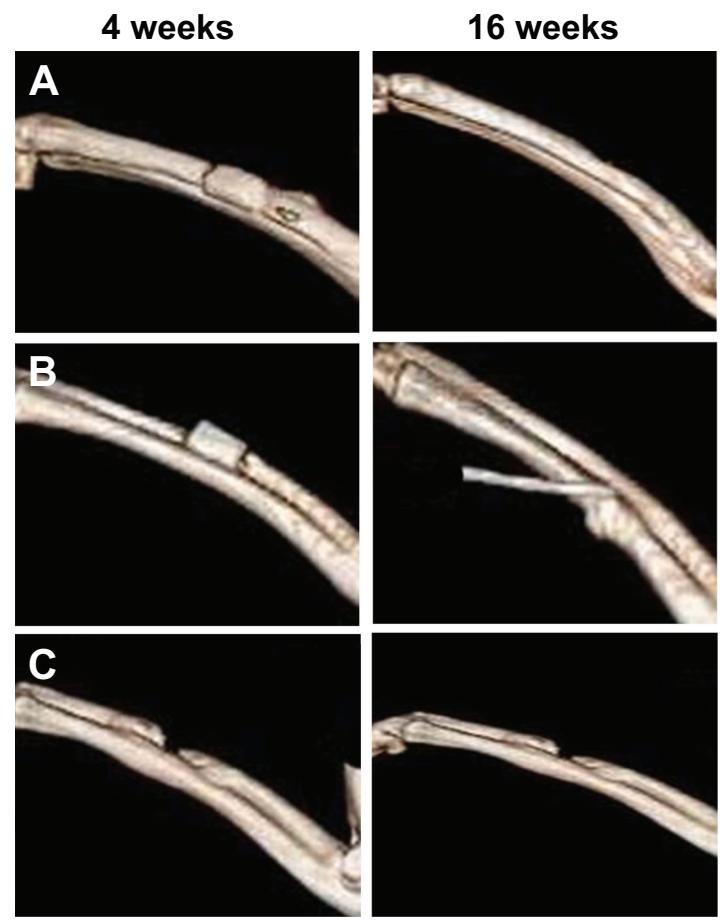

Figure 5 Three-dimensional tomographic images of the segmental radius at 4 and 16 weeks.

Notes: (A) BMP2-loaded hollow HA microspheres; (B) hollow HA microspheres without BMP2; (C) soluble BMP2 without a carrier.

Abbreviations: HA, hydroxyapatite; BMP2, bone morphogenetic protein 2. 


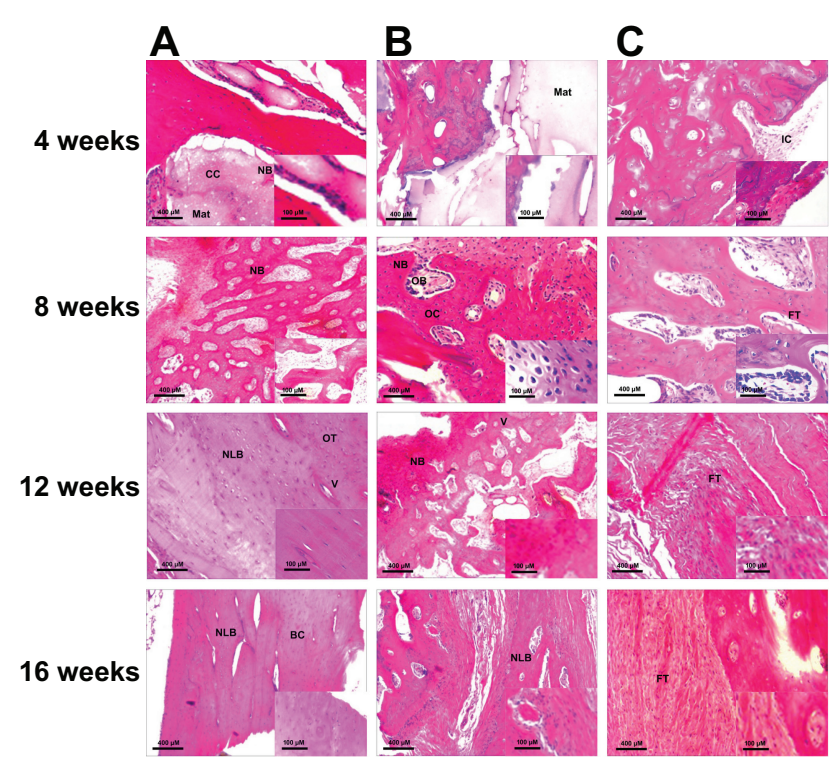

Figure 6 Histological evaluation of three groups at 4, 8, 12, and 16 weeks. Notes: (A) BMP2-loaded hollow HA microspheres; (B) hollow HA microspheres without BMP2; (C) soluble BMP2 without a carrier. Scale bars: $400 \mu \mathrm{m}, 10 \times$ magnification; $100 \mu \mathrm{m}, 40 \times$ magnification.

Abbreviations: $\mathrm{BC}$, blood cells; $\mathrm{BMP} 2$, bone morphogenetic protein 2; CC, chondrocytes; FT, fibrous tissue; HA, hydroxyapatite; IC, inflammatory cells; Mat, material; NB, new bone; NLB, new lamellar bone; OB, osteoblasts; OC, osteocytes; OT, osteon; $\mathrm{V}$, vessel.

\section{Radionuclide bone imaging}

Most of the radionuclide agents accumulated in the blood pool images. Organs and soft tissues over the body were clear with increased radioactivity. In contrast, radioactivity in the bones was too low to reveal a clear outline. The counts from ROI at the fractured side increased and reached a peak at 8 weeks, and decreased thereafter. There were significant differences of ROI counts among the three groups at each time point $(\mathrm{A}>\mathrm{B}>\mathrm{C}, P<0.05)$ (Figure 7).

In the static phase, the radionuclide agents were mostly accumulated in the bones. Kidney and bladder were clearly revealed as these organs are responsible for clearance. There were significant differences in the ROI counts from ROI at the fractured side among the three groups at each time point $(\mathrm{A}>\mathrm{B}>\mathrm{C}, P<0.05)$ (Figure 7B).

\section{Flexural strength}

The flexural strength of the newly regenerated bones was examined by biomechanical test with results shown in Figure 8 .

Table 2 Percentage of new bone formation (mean \pm standard deviation)

\begin{tabular}{lllll}
\hline Group & 4 weeks & $\mathbf{8}$ weeks & I 2 weeks & 16 weeks \\
\hline A & $30.4 \pm 10.1^{\mathrm{a}, \mathrm{b}}$ & $49.2 \pm 11.2^{\mathrm{a}, \mathrm{b}}$ & $79.2 \pm 10.3^{\mathrm{a}, \mathrm{b}}$ & $102.2 \pm 4.3^{\mathrm{a}, \mathrm{b}}$ \\
B & $21.7 \pm 8.3^{\mathrm{a}}$ & $40.1 \pm 10.2^{\mathrm{a}}$ & $63.9 \pm 9.2^{\mathrm{a}}$ & $85.2 \pm 9.2^{\mathrm{a}}$ \\
C & $8.2 \pm 5.3$ & $20.3 \pm 5.3$ & $23.3 \pm 6.2$ & $29.3 \pm 4.3$ \\
\hline
\end{tabular}

Notes: a $A$ or $B$ versus $C, P<0.05$; ${ }^{b} A$ versus $B, P<0.05 ; n=4 /$ group/time point.
The maximum load values in groups A and B continuously increased during the time course of 4 to 16 weeks. At each time point, the maximum load value in group $\mathrm{A}$ was always higher than in group $\mathrm{B}(P<0.05)$, indicating that new bones stimulated by BMP2 in group A grew faster and better.

\section{Discussion}

Limitations associated with autogenic and allogenic bone grafts have indicated the need for synthetic bone graft substitutes. Biocompatibility, osteoconductivity, osteoinductivity, and osteogenicity are several important parameters that assess the quality of artificial bone grafts for large bone defects. ${ }^{4}$ Over 20 years of discovery and development, HA has demonstrated the advantages as an osteoconductive matrix and a carrier material for BMP2-like bone growth factor delivery. ${ }^{10,20-22}$ However, additional efforts are still needed to fabricate an ideal HA system that controls the release of BMP2 at clinically desirable rates for bone regeneration.

The present study shows that hollow HA microspheres, prepared by a low-temperature glass conversion method, can provide a promising matrix for bone regeneration. Our XRD and FTIR spectroscopy results have confirmed that they are composed of HA, and are likely to be biocompatible and osteoconductive. More importantly, the unique structural features of hollow HA microspheres, such as a mesoporous shell with a high surface area, support high capacity for BMP2 loading and long-time sustained release of the protein. Our studies have shown that BMP2 is continuously but slowly released from loaded hollow HA microspheres over 40 days when incubated in PBS (Figure 2). The release speed, accumulative release amount, and sustained time have been improved over previous studies that use nanostructured HA or calcium phosphate cement as BMP2 carriers, and show limited short-term release. ${ }^{38-39}$ Like other HA carrier materials,${ }^{40}$ hollow HA microspheres initiated a burst release of BMP2 within 48 hours, which is often required to induce significant bone formation. ${ }^{41-42}$ However, a high-burst release of BMP 2 can potentially cause significant adverse biological effects. If required, the initial release of BMP2 from hollow HA microspheres can be optimized by adjusting either the amount of BMP2 loaded, the composition and structure of the HA with varying amounts of carbonate substitution, or tethering other polymer materials. ${ }^{17}$

This study also showed that BMP2-loaded hollow HA microspheres had a high capacity to regenerate bone in vivo, when compared to hollow HA microspheres without BMP2 or soluble BMP2 without a carrier. As early as 4 weeks, we 

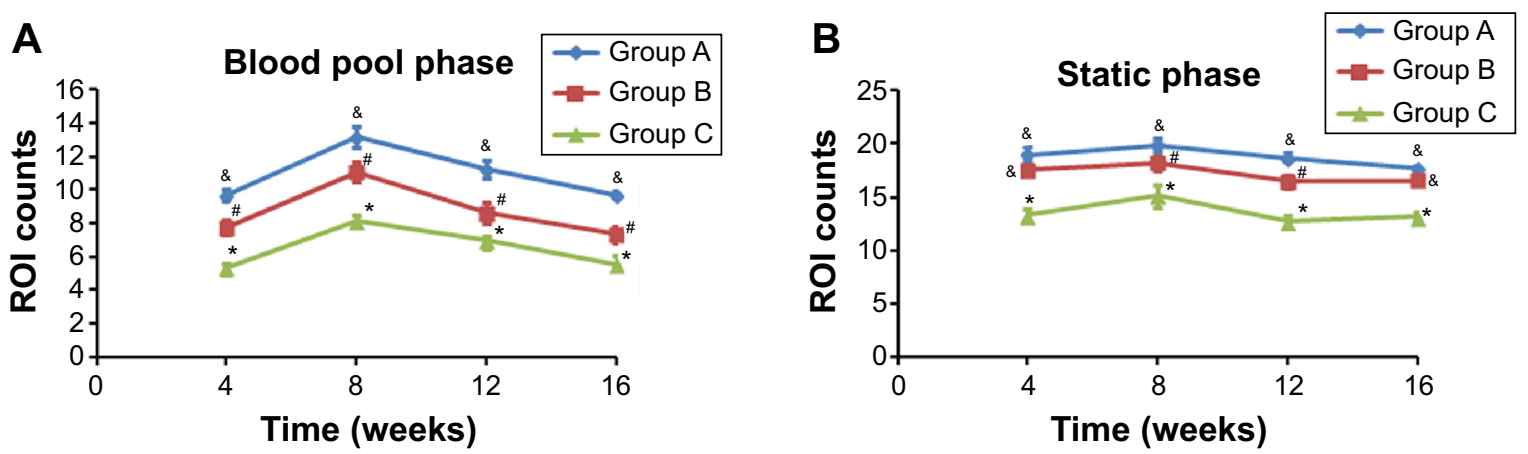

Figure 7 Counts from $\mathrm{ROI}$ at the fractured side.

Notes: (A) Blood pool phase; (B) static phase. Group A: BMP2-loaded hollow HA microspheres; Group B hollow HA microspheres without BMP2; Group C soluble BMP2 without a carrier. Different symbols ( ${ }^{*},{ }^{*}$ and $\left.{ }^{*}\right)$ represent different $\mathrm{ROI}$ counts at each time point $(P<0.05)$. N=4/group/time point.

Abbreviations: BMP2, bone morphogenetic protein 2; HA, hydroxyapatite; ROI, region of interest.

observed both HA degradation and new bone formation in the group of BMP2-loaded microspheres. In general, the degradation of HA is a long-term process in a physiological environment without involvement of osteoclasts and
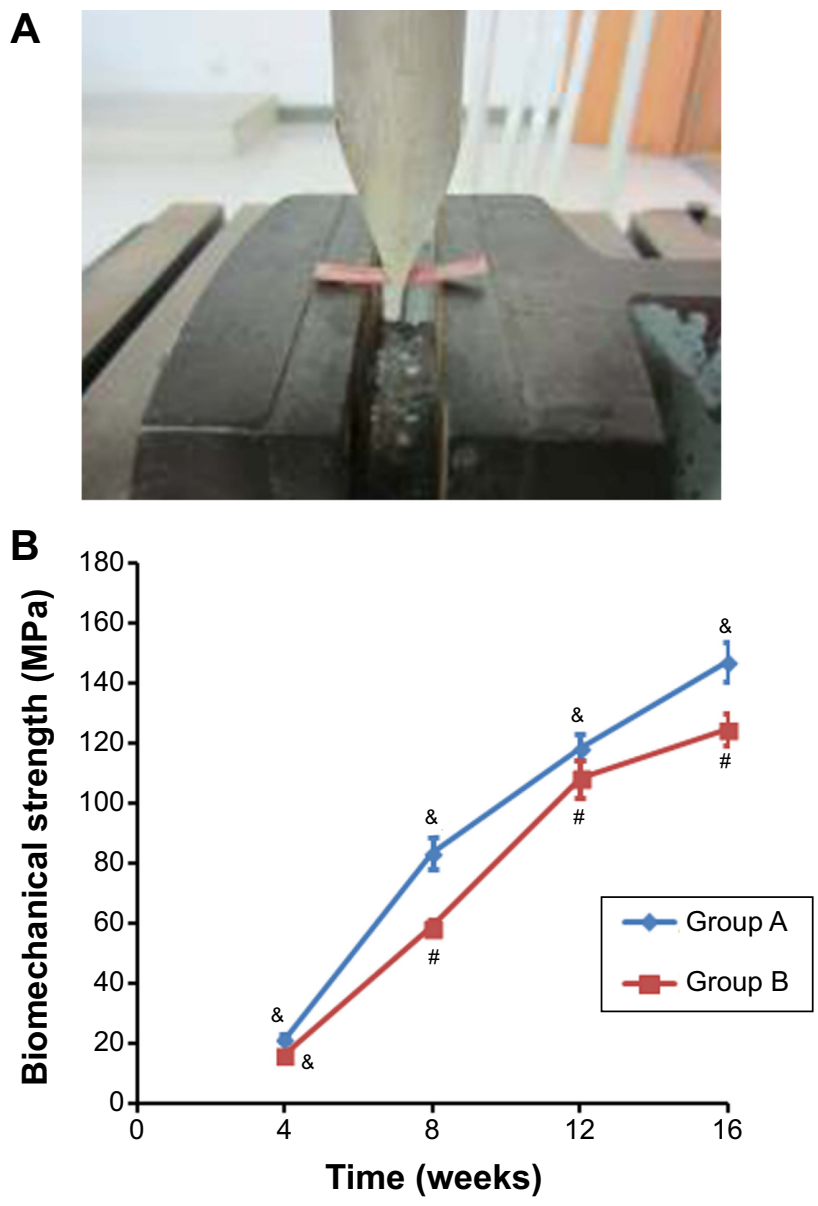

Figure $\mathbf{8}$ Biomechanical test of defective radius.

Notes: (A) mechanical testing facility; (B) the maximum flexural strength of defective radius. Group A: BMP2-loaded hollow HA microspheres; Group B, hollow HA microspheres without BMP2. Different symbols ( ${ }^{\&}$ and $\left.{ }^{\#}\right)$ represent different biomechanical strengths at each time point $(P<0.05)$. $N=4 /$ group/time point. Abbreviations: BMP2, bone morphogenetic protein 2; HA, hydroxyapatite. macrophages. ${ }^{43-44}$ The quick HA biodegradation in the BMP2-loaded microsphere group suggests an early bone remodeling process involving the participation of both osteoclasts and osteoblasts. Based on the data in Figures 5 and 6, a general equilibrium between bone formation and resorption appears to be established between 4 and 8 weeks in this group, and HA microspheres disappear at about 12 weeks. This degradation/formation dynamic profile is important in a bone repair process to ensure complete removal of implanted materials and regeneration of new bone, which can be further optimized by obtaining an appropriate initial burst and sustained release of BMP2.

In the current study, no inflammatory response or immunologic rejection reaction was observed after the implantation, suggesting that the hollow HA microspheres and animal tissues were biocompatible. As reported previously, ${ }^{45-46}$ ALP activity is a biochemical marker for the differentiation of mesenchymal stem cells into an osteoblast phenotype and, accordingly, bone regeneration. The higher serum ALP level was detected as early as 4 weeks in the group of BMP2loaded hollow HA microspheres compared with two other groups, showing the best therapeutic response in this group. This indicates that both BMP2 and hollow HA microspheres contribute to the enhancement of new bone formation. As noted in a previous study, ${ }^{47}$ the time at which exogenous BMP2 is administrated can be critical for fracture repair. The administration of BMP2 at the time of surgery (day 0 ) or in the early fracture healing phase (day 4) was found to enhance periosteal and endosteal callus formation, bone mineral content, and biomechanical properties when compared to later administration of BMP2 (day 8). The sustained and controlled delivery of BMP2 from different carriers has shown excellent potential for enhancing bone regeneration. ${ }^{48-50}$ However, an additional factor that BMP2-loaded micro- 
spheres could contribute to the enhanced bone repair might be the critical role played by the immobilized BMP2 when compared to the released BMP2.

It has been suggested that BMPs associated with the extracellular matrices were involved in the induction of osteoblastic differentiation of cells in the osteoblast lineage, an essential process for bone formation. ${ }^{51}$ Further studies are required to verify this hypothesis.

Besides inducing bone growth, BMP2 and other BMPs were reported to stimulate the increase of vascular endothelial growth factor during bone formation..$^{52-53}$ The formation of capillaries can provide sufficient nutrition for osteocytes. On the other hand, degradable microspheres permit robust cell infiltration at an early stage, leaving enough space for cell migration, attachment, and differentiation. Thus, BMP2loaded hollow HA microspheres succeed in inducing ectopic bone formation. In conclusion, the current study has demonstrated that hollow HA microspheres can serve as a bioactive and osteoconductive carrier for BMP2-like growth factor in bone regeneration, warranting further development of hollow HA microspheres as potential bone graft substitutes.

\section{Acknowledgments}

We thank Rong Xu, Haitao Mei, and Xiaofu Lin for their excellent technical support. We also appreciate Dr Dave Gold's careful reading of this manuscript.

\section{Author contributions}

LX and AY conceived and designed the study; JZ, AY, JL, ZT, and LY performed the experiments; LX, JZ, AY, JL, ZT, QT, and LY analyzed and interpreted the data. All authors wrote and revised the paper. In addition, all authors approved the published version of the paper and agreed to be accountable for full aspects of the work.

\section{Disclosure}

The authors report no conflicts of interest in this work.

\section{References}

1. Giannoudis PV, Dinopoulos H, Tsiridis E. Bone substitutes: an update. Injury. 2005;36 Suppl 3:S20-S27.

2. Bauer TW, Muschler GF. Bone graft materials. An overview of the basic science. Clin Orthop Relat Res. 2000(371):10-27.

3. Fleming JE Jr, Cornell CN, Muschler GF. Bone cells and matrices in orthopedic tissue engineering. Orthop Clin North Am. 2000;31(3):357-374.

4. Laurencin C, Khan Y, El-Amin SF. Bone graft substitutes. Expert Rev Med Devices. 2006;3(1):49-57.

5. Perry CR. Bone repair techniques, bone graft, and bone graft substitutes. Clin Orthop Relat Res. 1999;(360):71-86.
6. Zimmermann G, Moghaddam A. Allograft bone matrix versus synthetic bone graft substitutes. Injury. 2011;42 Suppl 2:S16-S21.

7. Crowley C, Wong JM, Fisher DM, Khan WS. A systematic review on preclinical and clinical studies on the use of scaffolds for bone repair in skeletal defects. Curr Stem Cell Res Ther. 2013;8(3):243-252.

8. Moore WR, Graves SE, Bain GI. Synthetic bone graft substitutes. ANZ J Surg. 2001;71(6):354-361.

9. Fisher DM, Wong JM, Crowley C, Khan WS. Preclinical and clinical studies on the use of growth factors for bone repair: a systematic review. Curr Stem Cell Res Ther. 2013;8(3):260-268.

10. Kirker-Head CA. Potential applications and delivery strategies for bone morphogenetic proteins. Adv Drug Deliv Rev. 2000;43(1):65-92.

11. Seeherman HJ, Bouxsein M, Kim H, et al. Recombinant human bone morphogenetic protein-2 delivered in an injectable calcium phosphate paste accelerates osteotomy-site healing in a nonhuman primate model. J Bone Joint Surg Am. 2004;86-A(9):1961-1972.

12. Bessa PC, Casal M, Reis RL. Bone morphogenetic proteins in tissue engineering: the road from the laboratory to the clinic, part I (basic concepts). J Tissue Eng Regen Med. 2008;2(1):1-13.

13. Wang EA, Rosen V, D'Alessandro JS, et al. Recombinant human bone morphogenetic protein induces bone formation. Proc Natl Acad Sci U S A. 1990;87(6):2220-2224.

14. Wozney JM, Rosen V. Bone morphogenetic protein and bone morphogenetic protein gene family in bone formation and repair. Clin Orthop Relat Res. 1998;(346):26-37.

15. McKay WF, Peckham SM, Badura JM. A comprehensive clinical review of recombinant human bone morphogenetic protein-2 (INFUSE Bone Graft). Int Orthop. 2007;31(6):729-734.

16. Fu H, Rahaman MN, Day DE, Brown RF. Hollow hydroxyapatite microspheres as a device for controlled delivery of proteins. $J$ Mater Sci Mater Med. 2011;22(3):579-591.

17. Shiels SM, Solomon KD, Pilia M, Appleford MR, Ong JL. BMP-2 tethered hydroxyapatite for bone tissue regeneration: coating chemistry and osteoblast attachment. J Biomed Mater Res A. 2012;100(11):3117-3123.

18. Babensee JE, McIntire LV, Mikos AG. Growth factor delivery for tissue engineering. Pharm Res. 2000;17(5):497-504.

19. Hong MH, Son JS, Kim KM, Han M, Oh DS, Lee YK. Drug-loaded porous spherical hydroxyapatite granules for bone regeneration. J Mater Sci Mater Med. 2011;22(2):349-355.

20. Woodard JR, Hilldore AJ, Lan SK, et al. The mechanical properties and osteoconductivity of hydroxyapatite bone scaffolds with multi-scale porosity. Biomaterials. 2007;28(1):45-54.

21. van Blitterswijk CA, Hesseling SC, Grote JJ, Koerten HK, de Groot K. The biocompatibility of hydroxyapatite ceramic: a study of retrieved human middle ear implants. J Biomed Mater Res. 1990; 24(4):433-453.

22. Suchanek W, Yoshimura M. Processing and properties of hydroxyapatitebased biomaterials for use as hard tissue replacement implants. J Mater Res. 1998;13(01):94-117.

23. Zhou H, Lee J. Nanoscale hydroxyapatite particles for bone tissue engineering. Acta Biomater. 2011;7(7):2769-2781.

24. Matsumoto T, Okazaki M, Inoue M, et al. Hydroxyapatite particles as a controlled release carrier of protein. Biomaterials. 2004;25(17): 3807-3812.

25. Ono I, Ohura T, Murata M, Yamaguchi H, Ohnuma Y, Kuboki Y. A study on bone induction in hydroxyapatite combined with bone morphogenetic protein. Plast Reconstr Surg. 1992;90(5):870-879.

26. Ripamonti U, Ma SS, van den Heever B, Reddi AH. Osteogenin, a bone morphogenetic protein, adsorbed on porous hydroxyapatite substrata, induces rapid bone differentiation in calvarial defects of adult primates. Plast Reconstr Surg. 1992;90(3):382-393.

27. Fu H, Rahaman MN, Brown RF, Day DE. Evaluation of BSA protein release from hollow hydroxyapatite microspheres into PEG hydrogel. Mater Sci Eng C Mater Biol Appl. 2013;33(4):2245-2250. 
28. Yao A, Ai F, Liu X, Wang D, Huang W, Xu W. Preparation of hollow hydroxyapatite microspheres by the conversion of borate glass at near room temperature. Mater Res Bull. 2010;45(1):25-28.

29. Day DE, White JE, Brown RF, McMenamin KD. Transformation of borate glasses into biologically useful materials. Glass Technology. 2003;44(2):75-81.

30. Huang W, Rahaman MN, Day DE, Miller BA. Strength of hollow hydroxyapatite microspheres prepared by a glass conversion process. J Mater Sci Mater Med. 2009;20(1):123-129.

31. Barrett EP, Joyner LG, Halenda PP. The Determination of Pore Volume and Area Distributions in Porous Substances. I. Computations from Nitrogen Isotherms. J Am Chem Soc. 1951;73(1):373-380.

32. Coleman NJ, Hench LL. A gel-derived mesoporous silica reference material for surface analysis by gas sorption 1. Textural features. Ceramics International. 2000;26(2):171-178.

33. van de Watering FC, Molkenboer-Kuenen JD, Boerman OC, van den Beucken JJ, Jansen JA. Differential loading methods for BMP-2 within injectable calcium phosphate cement. J Control Release. 2012;164(3):283-290.

34. Kerschan-Schindl K, Ruzicka M, Mahr S, et al. Unexpected low incidence of vertebral fractures in heart transplant recipients: analysis of bone turnover. Transpl Int. 2008;21(3):255-262.

35. Lane JM, Sandhu HS. Current approaches to experimental bone grafting. Orthop Clin North Am. 1987;18(2):213-225.

36. Yang F, Wang J, Hou J, Guo H, Liu C. Bone regeneration using cellmediated responsive degradable PEG-based scaffolds incorporating with rhBMP-2. Biomaterials. 2013;34(5):1514-1528.

37. Zhu W, Wang D, Peng L, et al. An experimental study on the application of radionuclide imaging in repairing bone defects. Artif Cells Nanomed Biotechnol. 2013;41(5):304-308.

38. Ruhe PQ, Boerman OC, Russel FG, Mikos AG, Spauwen PH, Jansen JA. In vivo release of rhBMP-2 loaded porous calcium phosphate cement pretreated with albumin. J Mater Sci Mater Med. 2006;17(10):919-927.

39. Autefage H, Briand-Mésange F, Cazalbou S, et al. Adsorption and release of BMP-2 on nanocrystalline apatite-coated and uncoated hydroxyapatite/beta-tricalcium phosphate porous ceramics. J Biomed Mater Res B Appl Biomater. 2009;91(2):706-715.

40. Rohanizadeh R, Chung K. Hydroxyapatite as a carrier for bone morphogenetic protein. J Oral Implantol. 2011;37(6):659-672.

41. Perri B, Cooper M, Lauryssen C, Anand N. Adverse swelling associated with use of rh-BMP-2 in anterior cervical discectomy and fusion: a case study. Spine J. 2007;7(2):235-239.
42. Carragee EJ, Hurwitz EL, Weiner BK. A critical review of recombinant human bone morphogenetic protein-2 trials in spinal surgery: emerging safety concerns and lessons learned. Spine J. 2011;11(6):471-491.

43. Rumpel E, Wolf E, Kauschke E, et al. The biodegradation of hydroxyapatite bone graft substitutes in vivo. Folia Morphol (Warsz). 2006;65(1):43-48.

44. Souto RM, Laz MM, Reis RL. Degradation characteristics of hydroxyapatite coatings on orthopaedic TiAlV in simulated physiological media investigated by electrochemical impedance spectroscopy. Biomaterials. 2003;24(23):4213-4221.

45. Marom R, Shur I, Solomon R, Benayahu D. Characterization of adhesion and differentiation markers of osteogenic marrow stromal cells. J Cell Physiol. 2005;202(1):41-48.

46. Stucki U, Schmid J, Hämmerle CF, Lang NP. Temporal and local appearance of alkaline phosphatase activity in early stages of guided bone regeneration. A descriptive histochemical study in humans. Clin Oral Implants Res. 2001;12(2):121-127.

47. Murnaghan M, McIlmurray L, Mushipe MT, Li G. Time for treating bone fracture using rhBMP-2: a randomised placebo controlled mouse fracture trial. J Orthop Res. 2005;23(3):625-631.

48. Chen RR, Mooney DJ. Polymeric growth factor delivery strategies for tissue engineering. Pharm Res. 2003;20(8):1103-1112.

49. La WG, Kang SW, Yang HS, et al. The efficacy of bone morphogenetic protein-2 depends on its mode of delivery. Artif Organs. 2010;34(12):1150-1153.

50. Srouji S, Ben-David D, Lotan R, Livne E, Avrahami R, Zussman E. Slow-release human recombinant bone morphogenetic protein-2 embedded within electrospun scaffolds for regeneration of bone defect: in vitro and in vivo evaluation. Tissue Eng Part A. 2011;17(3-4):269-277.

51. Suzawa M, Takeuchi Y, Fukumoto S, et al. Extracellular matrixassociated bone morphogenetic proteins are essential for differentiation of murine osteoblastic cells in vitro. Endocrinology. 1999; 140(5):2125-2133.

52. Deckers MM, van Bezooijen RL, van der Horst G, et al. Bone morphogenetic proteins stimulate angiogenesis through osteoblastderived vascular endothelial growth factor A. Endocrinology. 2002;143(4):1545-1553.

53. Ferrara N. Vascular endothelial growth factor: basic science and clinical progress. Endocr Rev. 2004;25(4):581-611.
International Journal of Nanomedicine

\section{Publish your work in this journal}

The International Journal of Nanomedicine is an international, peerreviewed journal focusing on the application of nanotechnology in diagnostics, therapeutics, and drug delivery systems throughout the biomedical field. This journal is indexed on PubMed Central, MedLine, CAS, SciSearch ${ }^{\circledR}$, Current Contents ${ }^{\circledR} /$ Clinical Medicine,

\section{Dovepress}

Journal Citation Reports/Science Edition, EMBase, Scopus and the Elsevier Bibliographic databases. The manuscript management system is completely online and includes a very quick and fair peer-review system, which is all easy to use. Visit http://www.dovepress.com/ testimonials.php to read real quotes from published authors. 